\title{
Effects of age on aerobic capacity in heart failure patients under beta-blocker therapy: Possible impact in clinical decision-making?
}

Emmanuel Gomes Ciolac ${ }^{1}$, Edimar Alcides Bocchi ${ }^{2}$, Miguel Morita Fernandes da Silva ${ }^{2}$, Aline Cristina Tavares ${ }^{2}$, Iram Soares Teixeira-Neto ${ }^{2}$, Guilherme Veiga Guimarães ${ }^{2}$

${ }^{1}$ Exercise and Chronic Disease Research Laboratory, Physical Education Department,

School of Sciences, São Paulo State University - UNESP, Bauru, Brazil

${ }^{2}$ Heart Institute (InCor) - Hospital das Clínicas da Faculdade de Medicina, University of São Paulo, Sao Paulo, Brazil

\begin{abstract}
Background: Heart failure (HF) is associated with impaired maximal aerobic capacity as indicated by decreases in peak oxygen uptake (peak $\mathrm{VO}_{2}$ ). Considering that aging by itself has a negative effect on this variable, the evaluation of maximum capacity is often questioned because current predicted peak $\mathrm{VO}_{2}$ is based on subjects without heart disease or $\beta$-blocker therapy. In contrast, if decline in predicted and attained peak $\mathrm{VO}_{2}$ were age-related, proportionally, loss of aerobic function (predicted peak $\mathrm{VO}_{2}, \%$ ) would remain stable over time in these patients. The purpose of this investigation is to assess the effects of age on peak $\mathrm{VO}_{2}$ in $\mathrm{HF}$ patients taking $\beta$-blockers.
\end{abstract}

Methods: We retrospectively evaluated 483 (132 female) patients (aged 20-88 years, LVEF $31 \pm 11 \%)$ with non-ischemic $(n=362)$, ischemic $(n=74)$ and Chagas-related HF $(n=47)$ who had been submitted to an incremental cardiopulmonary exercise testing on a motorized treadmill. Linear regression was used to develop the equation to predict peak $\mathrm{VO}_{2}$, based on age.

Results: Peak $\mathrm{VO}_{2}$ decreased $0.9 \mathrm{~mL} / \mathrm{min} / \mathrm{kg}$ per age-decade, maximum $\mathrm{HR}$ also decreased with aging and $\mathrm{VE} / \mathrm{VCO}_{2}$ slope was similar among all decades. The predicted new $\beta$-blocker equation to peak $\mathrm{VO}_{2 b b}$ was $20.934-0.092 \times$ age.

Conclusions: Clinical interpretation of aerobic capacity impairment is influenced by aging in $\mathrm{HF}$ patients. This evidence must be considered when using peak $\mathrm{VO}_{2}$ for prognostic stratification and clinical decision-making in patients with HF under $\beta$-blocker therapy. (Cardiol J 2013; 20, 6: 655-661)

Key words: aging, $\beta$-blocker therapy, cardiopulmonary exercise test, cardiorespiratory fitness, heart failure

Address for correspondence:

Dr Guilherme Veiga Guimarães, Rua Dr Baeta Neves, 98, São Paulo/SP, Brazil, CEP 05444-050, tel/fax: +55 11 2661-5502, e-mail: gvguima@usp.br

Prof. Emmanuel Gomes Ciolac, Universidade Estadual Paulista - UNESP - Departamento de Educação Física, Av. Engenheiro Luiz Edmundo Carrijo Coube 14-06, Bauru/SP, Brazil, CEP 17033-360, tel/fax: +55 14 3103-6082, e-mail: ciolac@fc.unesp.br

Received: 13.02.2013 Accepted: 11.05.2013 


\section{Introduction}

Chronic heart failure (HF) is an increasingly common disorder in population, which causes high mortality and morbidity, despite modern developments in medical therapy [1-4]. The primary symptoms of chronic $\mathrm{HF}$ are exertional fatigue and dyspnea due to a reduction in exercise tolerance [1]. Additional traits, as age, gender, weight, body surface area and muscle mass, can also be correlated to functional capacity in patients with $\mathrm{HF}[5,6]$.

Indeed, performing the cardiopulmonary exercise testing (CPX) became increasingly important in order to provide objective and reproducible measurement of exercise limitation [1] and to identify individuals suffering from $\mathrm{HF}$ with poor prognosis $[1,6]$. Among exercise variables, the strongest and most consistent predictors of death are peak oxygen consumption (peak $\mathrm{VO}_{2}$ ) $[1,4$, 6], $\mathrm{VO}_{2}$ at the ventilatory threshold, percentage of age-predicted maximal heart rate (HR) and $\mathrm{VE} / \mathrm{VCO}_{2}$ slope [6, 7].

These data have also influence on the chosen treatment. In the early 90 's, it was shown that patients with severe left ventricular dysfunction and peak $\mathrm{VO}_{2}<14 \mathrm{~mL} / \mathrm{min} / \mathrm{kg}$ would benefit from cardiac transplantation $[1,8]$. More recently, a lower cutoff for peak $\mathrm{VO}_{2}(<12.5 \mathrm{~mL} / \mathrm{min} / \mathrm{kg})$ has been identified as predictor of mortality in patients with HF, taking $\beta$-blocker agents [9].

Nevertheless, a progressive decline in cardiovascular system occurs with advancing age [10]. Age itself is an independent morbidity and mortality risk factor for a long list of diseases, hospitalization and length of hospitalization [11]. Physiological changes that occur during the aging process regarding quality of life and functional independence are muscle intrinsic abnormalities, low muscle mass or muscle perfusion [3], declining in muscle strength and in aerobic capacity, indexed as peak $\mathrm{VO}_{2}[5,12,13]$.

A few studies demonstrated that longitudinal rate of declining in peak $\mathrm{VO}_{2}$ is on average $8 \%$ to $10 \%$ per decade in the general population and, at the age of 60 , it is approximately two-thirds of that at $20[10,14]$. Recently it has been reported that peak $\mathrm{VO}_{2}$ decreases with age in HF patients, however, these reports came from studies with patients classified as young, middle-aged and older, and the peak $\mathrm{VO}_{2}$ was assessed using either a treadmill or cycle ergometer CPX $[15,16]$. On the other hand, there are no trials showing the effect of age by decade on peak $\mathrm{VO}_{2}$ in $\mathrm{HF}$ patients. It is possible that age can influence the peak $\mathrm{VO}_{2}$, as well as the cutoff point for cardiac transplant in patients suffering from HF. The purpose of this investigation is to assess the effects of age on peak $\mathrm{VO}_{2}$ in $\mathrm{HF}$ patients taking $\beta$-blockers.

\section{Methods}

\section{Population and study design}

A retrospective analysis was performed in consecutive patients with systolic HF referred to heart transplant, from 1999 to 2009. Inclusion criteria included clinical and pharmacological stability for at least 3 months prior CPX, age $\geq 20$ years, left ventricular ejection fraction (LVEF) $<45 \%$, New York Heart Association functional class I-III and no participation in regular physical activity ( $\geq 30$ min 3 times a week). Patients with cardiac device system (pacemaker or implantable defibrillator), CPX interrupted due to hemodynamic or electrocardiographic complications, respiratory exchange ratio $(\mathrm{RER})<1.0$, neuromuscular or respiratory limitations were excluded from the study.

A total of 655 clinically and pharmacologically stable HF patients underwent CPX during this period. One hundred seventy two patients were excluded from analysis because they were, either, under regular physical activity $(n=40)$, were under 20 years old $(n=25)$, had no optimized drug therapy $(n=10)$, or interrupted test due to hemodynamic or electrocardiographic complications $(\mathrm{n}=40)$, respiratory limitations $(\mathrm{n}=10), \mathrm{LVEF}$ $\geq 45 \%(\mathrm{n}=10)$, atrial fibrillation $(\mathrm{n}=20)$, and pacemaker or implantable defibrillator $(n=15)$. The final sample included 483 patients with systolic $\mathrm{HF}$ aged from 20 to 88 years, with stable dose of $\beta$-blocker for more than 3 months prior to the $\mathrm{CPX}$. The patients were enrolled in six age groups ranging from 20 to 29,30 to 39,40 to 49,50 to 59 , 60 to 69 and $\geq 70$ years old. Clinical characteristics are listed in Table 1.

The review board of the ethical committee at our institution had approved the study and it is in accordance with the declaration of Helsinki.

\section{Exercise testing}

All referred patients had undergone maximal exercise testing using a modified Naughton protocol and a metabolic cart. CPX had been carried out on a programmable treadmill (TMX425 Stress Treadmill; TrackMaster, Newton, KS, USA) in a controlled-temperature room $\left(21-23^{\circ} \mathrm{C}\right)$ with monitoring of cardiac rhythm (CardioSoft 6.5; GE Medical Systems IT, Milwaukee, WI, USA) and blood pressure (Tango Stress BP; SunTech Medical 
Table 1. Baseline characteristics according to age decade.

\begin{tabular}{|c|c|c|c|c|c|c|}
\hline & $\begin{array}{c}20-29 \\
(n=28)\end{array}$ & $\begin{array}{c}30-39 \\
(n=67)\end{array}$ & $\begin{array}{c}40-49 \\
(n=152)\end{array}$ & $\begin{array}{c}50-59 \\
(n=143)\end{array}$ & $\begin{array}{c}60-69 \\
(n=75)\end{array}$ & $\begin{array}{c}\geq 70 \\
(n=18)\end{array}$ \\
\hline Sex (male/female) & $19 / 9$ & $49 / 18$ & $114 / 38$ & $96 / 47$ & $60 / 15$ & $12 / 6$ \\
\hline Body mass index $\left[\mathrm{kg} / \mathrm{m}^{2}\right]$ & $23 \pm 4$ & $26 \pm 5$ & $25 \pm 4$ & $26 \pm 5^{*}$ & $27 \pm 5^{*}$ & $27 \pm 4$ \\
\hline Hemoglobin [g/dL] & $13.6 \pm 1.4$ & $13.7 \pm 1.4$ & $13.5 \pm 1.8$ & $13.6 \pm 1.6$ & $13.8 \pm 1.3$ & $13.7 \pm 2.2$ \\
\hline LVEF [\%] & $27 \pm 8$ & $30 \pm 10$ & $28 \pm 11$ & $30 \pm 13$ & $30 \pm 12$ & $25 \pm 7$ \\
\hline Heart rate rest [bpm] & $86 \pm 21$ & $79 \pm 15$ & $76 \pm 15^{*}$ & $75 \pm 15^{*}$ & $76 \pm 18^{*}$ & $79 \pm 12$ \\
\hline \multicolumn{7}{|l|}{ Etiology: } \\
\hline Idiophatic & 23 & 48 & 114 & 107 & 62 & 10 \\
\hline Ischemic & 3 & 13 & 23 & 22 & 8 & 5 \\
\hline Chagas & 2 & 8 & 15 & 14 & 5 & 3 \\
\hline \multicolumn{7}{|l|}{ Medication [\%]: } \\
\hline Beta-blocker & 100 & 100 & 100 & 100 & 100 & 100 \\
\hline Diuretics & 76 & 73 & 70 & 69 & 72 & 77 \\
\hline ACE-I/ARB & 86 & 87 & 80 & 81 & 79 & 88 \\
\hline Digoxin & 43 & 38 & 41 & 40 & 37 & 38 \\
\hline Aldosterone & 46 & 40 & 39 & 37 & 40 & 42 \\
\hline Nitrate & 2.5 & 2.1 & 3.2 & 3.3 & 2.8 & 2.1 \\
\hline Amrinone & 1 & 1.8 & 2.1 & 2.0 & 1 & 1 \\
\hline Anticoagulants & 0 & 1.5 & 2.3 & 2.5 & 1 & 0 \\
\hline
\end{tabular}

${ }^{a}$ Significant difference in relation to age group 20-29 ( $\left.p=0.01\right)$; LVEF - left ventricular ejection fraction; ACE-I - angiotensin converting enzyme inhibitor; ARB - angiotensin receptor blocker

Inc, Morrisville, NC, USA) as previously described [17]. The 12-lead electrocardiogram and HR had been monitored in the standing position before and throughout the exercise and recovery period. Ventilation (VE), oxygen uptake $\left(\mathrm{VO}_{2}\right)$ and carbon dioxide output $\left(\mathrm{VCO}_{2}\right)$ had been measured breath-by-breath using a computerized system (Vmax Encore29; SensorMedics Corp., Yorba Linda, CA, USA). The RER had been recorded at each average sample obtained during each stage of the protocol. The highest $\mathrm{VO}_{2}$ uptake level ( 1 min mean) at the end of exercise was considered the peak $\mathrm{VO}_{2}$, and the $\mathrm{VE} / \mathrm{VCO}_{2}$ slope was calculated by automatic linear regression fitting with the breath-by-breath values obtained throughout the whole exercise. Patients had been instructed and encouraged to exercise to their maximum capacity.

The predicted peak $\mathrm{VO}_{2}$ was calculated according to normative values to age, sex and body weight by Wasserman et al. [18]. The percentage of predicted peak $\mathrm{VO}_{2}$ was determined by dividing the weight normalized peak $\mathrm{VO}_{2}$ by the predicted peak $\mathrm{VO}_{2}$ and then multiplying it by 100 . Predicted maximum heart rate $\left(\mathrm{HR}_{\max }\right)$ was determined by the equation $\mathrm{HR}_{\max }=164-(0.7 \times$ age $)$, which was validated for patients receiving $\beta$-blocker therapy [19].

\section{Statistical analysis}

All data are reported as means \pm standard deviation and the statistical program SPSS 13.0 for Windows (SPSS Inc, Chicago, IL, USA) was used to perform statistical analysis. The Kolmogorov-Smirnov test was applied to ensure a Gaussian distribution of the results. One-way analysis of variance (ANOVA) was used to analyze differences in the subject's characteristics at baseline. Bonferroni post hoc analysis was used to determine significance of data that was indicated by one-way ANOVA. Pearson correlation was used to assess the relationship between age and both peak $\mathrm{VO}_{2}$ and $\mathrm{HR}_{\max }$, and between age and percent predicted for them. Linear regression was used to generate equation to predict peak $\mathrm{VO}_{2}$ from age for $\mathrm{HF}$ patients receiving $\beta$-blocker therapy. Then, we calculated the predicted peak $\mathrm{VO}_{2}$ using this linear regression for patients taking $\beta$-blocker agents $\left(\mathrm{VO}_{2 \mathrm{bb}}\right)$. The significance level was set at $\mathrm{p}<0.05$.

\section{Results}

The comparisons of clinical characteristics of categorized patients by age decades are listed in Table 1 . The percentage of subjects with non- 
Table 2. Cardiopulmonary exercise test variables according to age decade.

\begin{tabular}{lcccccc}
\hline & $\begin{array}{c}\mathbf{2 0 - 2 9} \\
(\mathbf{n}=\mathbf{2 8})\end{array}$ & $\begin{array}{c}\mathbf{3 0 - 3 9} \\
(\mathbf{n}=\mathbf{6 7})\end{array}$ & $\begin{array}{c}\mathbf{4 0 - 4 9} \\
(\mathbf{n}=\mathbf{1 5 2})\end{array}$ & $\begin{array}{c}\mathbf{5 0 - 5 9} \\
(\mathbf{n}=\mathbf{1 4 3})\end{array}$ & $\begin{array}{c}\mathbf{6 0 - 6 9} \\
(\mathbf{n}=\mathbf{7 5})\end{array}$ & $\begin{array}{c}\geq \mathbf{7 0} \\
(\mathbf{n}=\mathbf{1 8})\end{array}$ \\
\hline $\mathrm{HR}_{\max }$ & $129 \pm 29$ & $124 \pm 27$ & $123 \pm 23$ & $117 \pm 24$ & $116 \pm 27$ & $114 \pm 19$ \\
$\% \mathrm{HR}_{\max }$ & $89 \pm 19$ & $88 \pm 20$ & $93 \pm 17$ & $93 \pm 19$ & $97 \pm 22$ & $103 \pm 17$ \\
peak VO & $18.8 \pm 6.5$ & $17.5 \pm 5.7$ & $16.7 \pm 5.0$ & $16.2 \pm 4.5$ & $14.9 \pm 4.2^{\mathrm{a}, \mathrm{b}}$ & $13.0 \pm 2.4^{\mathrm{a}, \mathrm{b}, \mathrm{c}}$ \\
$\% \mathrm{VO}_{2 \text { pred }}$ & $46 \pm 14$ & $43 \pm 13$ & $44 \pm 11$ & $48 \pm 11$ & $48 \pm 12$ & $46 \pm 8$ \\
peak VO$_{2 \mathrm{bb}}{ }^{\mathrm{d}}$ & $18.5 \pm 0.27$ & $17.7 \pm 0.27$ & $16.8 \pm 0.25$ & $15.9 \pm 0.26$ & $15.0 \pm 0.27$ & $13.9 \pm 0.45$ \\
$\% \mathrm{VO}_{2 \text { predbb }}$ & $101 \pm 35$ & $99 \pm 32$ & $100 \pm 30$ & $102 \pm 30$ & $99 \pm 28$ & $94 \pm 18$ \\
$\mathrm{RER}$ & $1.06 \pm 0.05$ & $1.05 \pm 0.05$ & $1.07 \pm 0.06$ & $1.07 \pm 0.07$ & $1.06 \pm 0.06$ & $1.03 \pm 0.02$ \\
$\mathrm{VE} / \mathrm{VCO}_{2 \text { slope }}$ & $35 \pm 15$ & $35 \pm 13$ & $35 \pm 8$ & $36 \pm 10$ & $35 \pm 9$ & $35 \pm 9$ \\
\hline
\end{tabular}

$\mathrm{HR}_{\max }$ - maximum heart rate [bpm]; \% $\mathrm{HR}_{\max }$ - percent-predicted $\mathrm{HRmax}$; peak $\mathrm{VO}_{2}$ - peak oxygen consumption [mL/kg/min]; $\% \mathrm{VO}_{2 \text { pred }}$ - percent-predicted peak $\mathrm{VO}_{2} ;$ peak $\mathrm{VO}_{2 \mathrm{bb}}$ - peak $\mathrm{VO}_{2}$ estimated by $20.934-0.092 \times \mathrm{age}[\mathrm{mL} / \mathrm{kg} / \mathrm{min}] ; \%$ VO ${ }_{2 \text { predbb }}-$ percent-predicted peak $\mathrm{VO}_{2}$ using predicted peak $\mathrm{VO}_{2 \mathrm{bb}} ; \mathrm{RER}$ - respiratory exchange ratio; significant differences between age group: ${ }^{\mathrm{a}} 20-29,{ }^{\mathrm{b}} 30-39$, and ${ }^{\mathrm{C}} 40-49$; ' ${ }^{2}$ significant differences among all decades

-ischemic HF etiology, as well as male subjects was greatest in all decades. The body mass index was significantly lower in the 20-29 year group when compared to patients in the 50's and 60's decades. The resting HR was significantly higher in the 20's decade in relation to the 40's, 50's and 60 's. LVEF and HF pharmacological therapy were not different among the groups. All patients were taking $\beta$-blockers (carvedilol 80\%, bisoprolol 15\% and metaprolol 5\%) at maximum tolerated dose at the discretion of the treating physician.

Cardiopulmonary exercise test data are shown in Table 2. None of the exercise tests were terminated secondary to electrocardiogram criteria and all patients stopped it by fatigue symptoms. The peak $\mathrm{VO}_{2}$ was significantly lower among patients in the 60's and 70's decades in relation to the 20's, 30 's and 40 's. We also observed that peak $\mathrm{VO}_{2}$ decreased approximately $0.9 \mathrm{~mL} / \mathrm{kg} / \mathrm{min}$ by decade in this population. However, the percentage of the predicted peak $\mathrm{VO}_{2}$ and, the peak RER were similar in all groups, as well as their maximum and percentage of maximum HR. The other variable that was similar in all decades was $\mathrm{VE} / \mathrm{VCO}_{2}$ slope.

The linear regression analysis of peak $\mathrm{VO}_{2}$ vs. age is shown in Figure 1. The intercept and slope were $20.93 \pm 0.95$ and $-0.092 \pm 0.018$, respectively. So, the equation for estimated peak $\mathrm{VO}_{2 \mathrm{bb}}$ to $\mathrm{HF}$ patients in $\beta$-blocker therapy is $20.934-0.092 \times$ $\times$ age for whole population.

Table 2 shows the results of the new $\beta$-blocker prediction equation for peak $\mathrm{VO}_{2 \mathrm{~b}}$ using a computerized system in $\mathrm{HF}$ patients receiving $\beta$-blockers therapy underwent treadmill exercise testing. The peak $\mathrm{VO}_{2 \mathrm{~b}}$ was not significantly different from the peak $\mathrm{VO}_{2}$ measured in all age-decades. However, the peak $\mathrm{VO}_{2 \mathrm{~b}}$ was significantly different among

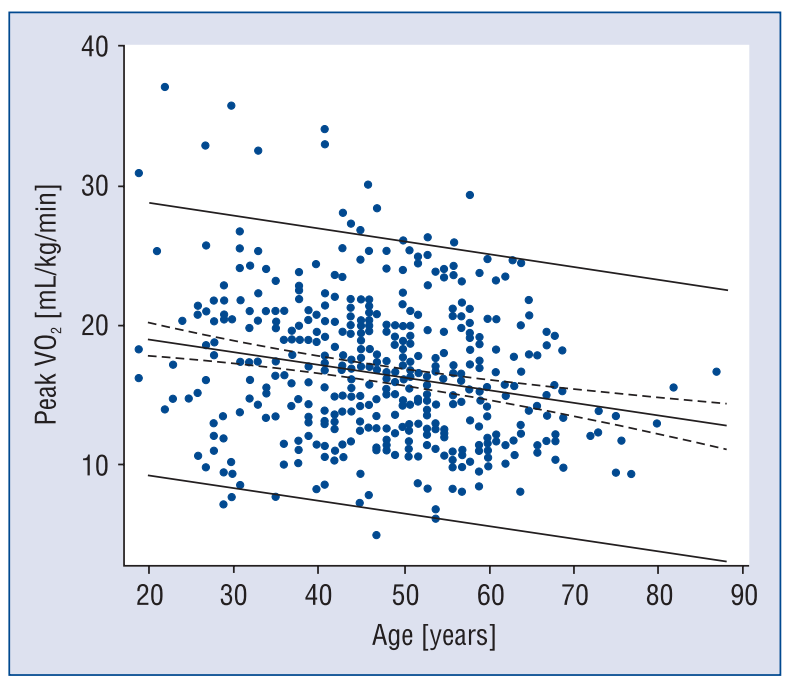

Figure 1. Linear regression equation of peak exercise oxygen consumption (peak $\mathrm{VO}_{2}$ ) versus age. Dashed line represent $95 \%$ confidence interval of the mean. From these data, a new equation was proposed: $\mathrm{VO}_{2 \mathrm{bb}}=$ $=20.934-0.092 \times$ age.

all groups. The Figure 2 shows the interrelation between age, $\mathrm{HR}_{\max }$ and peak $\mathrm{VO}_{2}$.

The correlations between age and peak $\mathrm{VO}_{2}$ $(\mathrm{r}=0.21, \mathrm{p}<0.0001)$, and $\mathrm{HR}_{\max }(\mathrm{r}=0.16, \mathrm{p}=$ $=0.0007)$ were weak although statistically significant (Fig. 3). The analysis for $\mathrm{VE} / \mathrm{VCO}_{2}$ slope did not show correlation with age $(r=0.01, \mathrm{p}=0.6)$.

\section{Discussion}

The primary finding of the present study was that peak $\mathrm{VO}_{2}$ decreased $0.9 \mathrm{~mL} / \mathrm{kg} / \mathrm{min}$ for every 10 -year increment in age in HF patients taking $\beta$-blockers. Additionally, our results show that aerobic function 


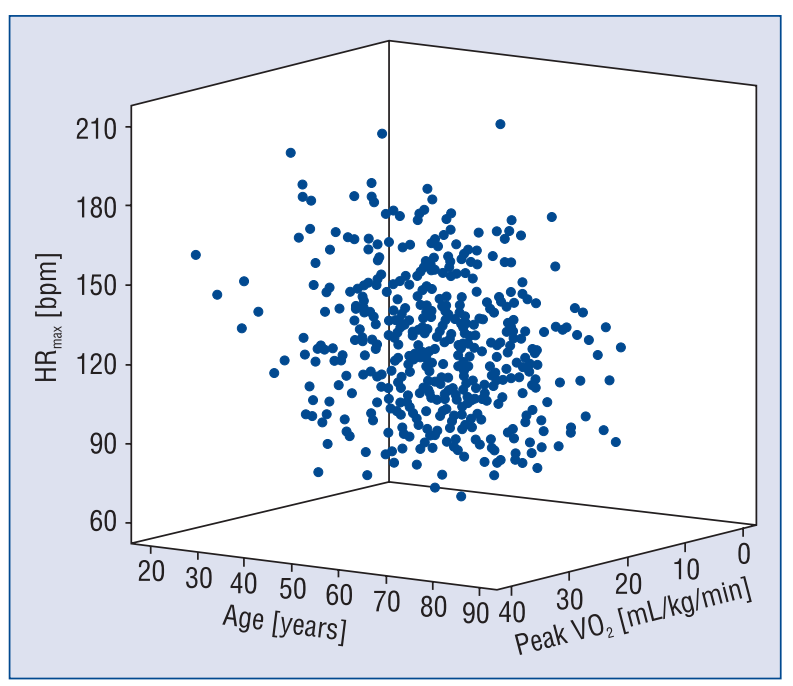

Figure 2. Interrelation among age, peak exercise oxygen consumption (peak $\mathrm{VO}_{2}$ ) and maximum heart rate $\left(\mathrm{HR}_{\text {max }}\right)$.

(\% predicted) did not differ among young, middle-aged and older patients with HF. The other finding in this investigation is that the new $\beta$-blocker equation for predicted peak $\mathrm{VO}_{2 \mathrm{~b}}$ in this specific population between 20 and 88 years old corresponds to 20.934 $-0.092 \times$ age. To the best of our knowledge, this is the first study to determine an equation to predict peak $\mathrm{VO}_{2}$ and compare the effects of age on physical capacity among different decades in HF patients undergoing a CPX performed on a treadmill in all cases.

Two previous studies that have investigated the effect of age in HF patients showed a reduction in aerobic capacity $[16,17]$. However, these authors analyzed these effects within broad aged groups and the exercise testing was completed using both treadmill and upright cycle ergometer. In spite of methodological differences, the decrease in value of peak $\mathrm{VO}_{2}$ was $1.0 \mathrm{~mL} / \mathrm{kg} / \mathrm{min}$ for every 7 years [16], which was similar to the findings in our study. The functional capacity is associated with age and begins to decline after age 30 , with a more exponential decrease in cardiorespiratory fitness and muscle strength after the age of 50 in apparently healthy individuals $[20,21]$. This represents a decline in peak $\mathrm{VO}_{2}$ on average of $8 \%$ to $10 \%$ per decade [10-12]. Hence, age itself is an independent predictor for peak $\mathrm{VO}_{2}$. In previous specific investigations about aerobic capacity and aging in $\mathrm{HF}$ $[16,17]$ it was reported that physiologic reserve in $\mathrm{HF}$ is very reduced, which is supported by our results. Progressive decline in peak $\mathrm{VO}_{2}$ reflects the degree of disease's severity and provides prognostic information in patients with HF [22].

However, our results demonstrated that the mean percent-predicted peak $\mathrm{VO}_{2}$ value for all groups was $45.8 \%$, which may suggest that these patients are already in their comfort zone, considering age-decades. On the other hand, when new $\beta$-blocker equation for predicted peak $\mathrm{VO}_{2 \mathrm{bb}}$ was used this reduction disappears. The peak $\mathrm{VO}_{2 b \mathrm{~b}}$ calculated by equation did not differ from the actual peak $\mathrm{VO}_{2}$ measured, so the percentage of predicted peak $\mathrm{VO}_{2 b \mathrm{~b}}$ is around $100 \%$. This finding itself indicates that both aerobic capacity and aerobic function, when adjusted by the equation, are in closer relationship with age than disease's severity in patients with HF. Moreover, $\mathrm{VE} / \mathrm{VCO}_{2}$ slope did not change among the

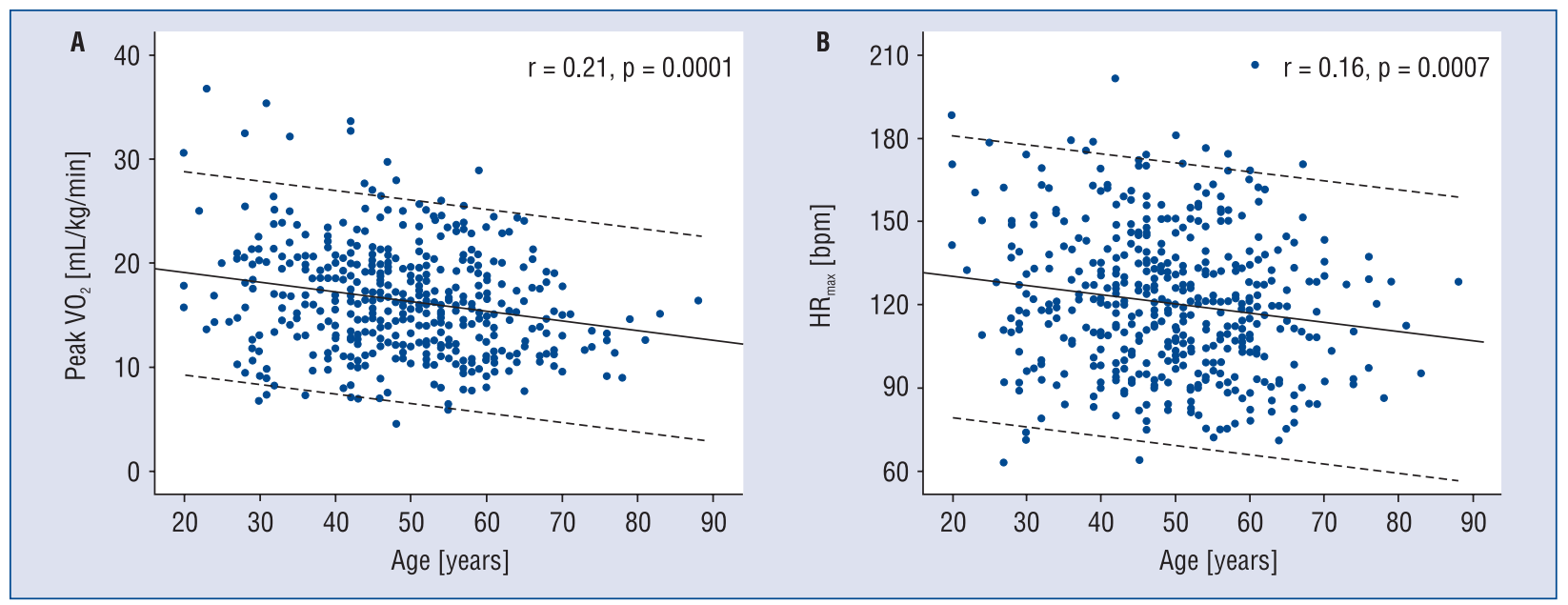

Figure 3. Relationship between age and: A. Peak exercise oxygen consumption (peak $\left.\mathrm{VO}_{2}\right)$; $B$. Maximum heart rate $\left(\mathrm{HR}_{\max }\right)$. There was a significant correlation between age and both $\mathbf{A}$ and $\mathbf{B}$. Dashed lines represent $95 \%$ prediction interval. 
age-decades, reinforcing the theory that the fall in peak $\mathrm{VO}_{2}$ is not related to worsening of $\mathrm{HF}$.

The results of the present study are according to our previous investigation, which showed a cutoff point for peak $\mathrm{VO}_{2}$ of $12.5 \mathrm{~mL} / \mathrm{kg} / \mathrm{min}$ in $\mathrm{HF}$ patients undertaking $\beta$-blockers as better midterm prognosis [8].

The effects of physiologic aging are associated to declining in exercise capacity, $\mathrm{HR}_{\max }$ and peak $\mathrm{VO}_{2}$ [11]. Although it was reported that the decline in peak $\mathrm{VO}_{2}$ seems to be primarily by reduction in $\mathrm{HR}_{\text {max }}$ [23], there was no significant difference in $\mathrm{HR}_{\text {max }}$ during age-decades among the groups.

The $\beta$-blocker therapy has become a primary pharmacologic intervention in patients with $\mathrm{HF}$ [24]. Previous report has shown that the maximal age-predicted HR depends on optimization of $\beta$-blocker dosing in HF patient $[2,25]$. In our study, the HR in maximal effort evaluation was $93.8 \pm 4.9 \%$ of the predicted in the whole sample, estimated by the specific equation to predict $\mathrm{HR}_{\max }$ in patients receiving this therapy [18]. Despite the tendency to HR decline during age-decades, the percentage of $\beta$-blocker predicted $\mathrm{HR}_{\max }$ in middle-aged and older tends to be higher, which may suggest reduced in chronotropic reserve over the years in HF patients taking $\beta$-blockers [26].

\section{Limitations of the study}

This is a retrospective study using selected patients with HF referred to heart transplant of a single center. All patients underwent a single treadmill CPX to assess aerobic capacity. Even though data collection is not planned and statistical analysis is exploratory, all patients underwent testing on the same equipment and by the same team, which eliminates the differences in data collection and conduction. Considering the high morbidity and mortality in this population, the functional capacity decrease is probably higher over time, since decompensated patients or with excessive limitation cannot be evaluated by exercise testing. However, our results are applicable to clinical setting where peak $\mathrm{VO}_{2}$ is an important prognostic parameter. Since present guidelines recommend cardiac rehabilitation for stable $\mathrm{HF}$ patients, excluding from analyses patients undergoing regular physical activity is a limitation. However, the inclusion of small number of patients undergoing regular physical activity could bias study results. Future studies focused in analyzing how age affects stable HF patients compliant to exercise/cardiac rehabilitation guidelines are thus necessary. The number of patients between 20-29 and $\geq 70$ years was relatively small in comparison to the other groups, but the analysis showed that the sample size was sufficient to detect difference. Values of peak $\mathrm{VO}_{2}$ are lower for women than men [27], however we did not analyze it separately due to the small number of women in the sample. Finally, the new equation for predicted peak $\mathrm{VO}_{2}$ in $\mathrm{HF}$ patients undertaking $\beta$-blockers is based on treadmill only and cannot be extrapolated to upright cycle ergometer exercise test.

\section{Clinical implication}

The present finding shows an inverse and decreased association between aerobic capacity and aging in HF patients taking $\beta$-blockers. This association derives from patients who underwent a treadmill CPX. The finding suggests that a reduction in peak $\mathrm{VO}_{2}$ higher than $0.9 \mathrm{~mL} / \mathrm{kg} / \mathrm{min}$ per decade may indicate a significant worsening in aerobic capacity and may not reflect the expected decline in aerobic function in HF patients. The similarity between measured and calculated peak $\mathrm{VO}_{2}$ in all age-decades suggests that there is no functional physiologic reserve associated to aging in HF. Peak $\mathrm{VO}_{2}$ is used for clinical decision-making regarding the need for cardiac transplantation in all age-decades. However, the cutoff value was determined in middle-aged $\mathrm{HF}$ patient predominantly. Therefore, we may speculate that age-decades difference in peak $\mathrm{VO}_{2}$ could be an important factor for clinical decision-making in patients with HF.

\section{Conclusions}

In summary, this investigation suggests that age-adjusted peak $\mathrm{VO}_{2}$ may describe more accurately the degree of aerobic capacity impairment in HF patients. This evidence should be considered when using the peak $\mathrm{VO}_{2}$ for prognostic stratification and clinical decision-making in patients with HF.

\section{Acknowledgements}

This work was supported by Fundação de Amparo à Pesquisa do Estado de São Paulo (FAPESP \# 2010/08554-7). Emmanuel G Ciolac was supported by Fundação de Amparo à Pesquisa during this Project (FAPESP \# 2012/02409-0). Guilherme V Guimarães was supported by Conselho Nacional de Pesquisa (CNPq \# 304733/2008-3).

Conflict of interest: none declared 


\section{References}

1. Mancini DM, Eisen H, Kussmaul W, Mull R, Edmunds H, Wilson JR. Value of peak exercise oxygen consumption for optimal timing of cardiac transplantation in ambulatory patients with heart failure. Circulation, 1991; 83: 778-786.

2. Carvalho VO. Bocchi EA. Guimarães GV. The Carvedilol's beta-blockade in heart failure and exercise training's sympathetic blockade in healthy athletes during the rest and peak effort. Cardiovascular Therapeutics, 2010; 28: 87-92.

3. Puntawangkoon C, Kitzman DW, Kritchevsky SB et al. Reduced peripheral arterial blood flow with preserved cardiac output during submaximal bicycle exercise in elderly heart failure. J Cardiovasc Magn Resonance, 2009; 18: 11-48.

4. Bocchi EA, Cruz F, Guimarães G et al. Long-term prospective, randomized, controlled study using repetitive education at six-month intervals and monitoring for adherence in heart failure outpatients: the REMADHE trial. Circ Heart Fail, 2008; 1: 115-124.

5. Morris CK, Myers J, Froelicher VF, Kawaguchi T, Ueshima K, Hideg A. Nomogram based on metabolic equivalents and age for assessing aerobic exercise capactiy in men. J Am Coll Cardiol, 1993; 22: 175-182.

6. Myers J, Gullestad L, Vagelos R et al. Clinical, hemodynamic, and cardiopulmonary exercise test determinants of survival in patients referred for evaluation of heart failure. Ann Intern Med, 1998; 129: 286-293.

7. Jaussaud J, Aimable L, Douard H. The time for a new strong functional parameter in heart failure: the VE/VCO2slope. Int J Cardiol, 2011; 147: 189-190.

8. Kokkinos P. Myers J. Faselis C et al. Exercise capacity and mortality in older men. A 20-year follow-up study. Circulation, 2010; 122: 790-797.

9. Guimaraes GV, d'Avila VM, Silva MS et al. A cutoff point for peak oxygen consumption in the prognosis of heart failure patients with beta-blocker therapy. Int J Cardiol, 2010; 145: 75-77.

10. Oxenham H, Sharpe N. Cardiovascular aging and heart failure. Eur J Heart Fail, 2003; 5: 427-434.

11. Priebe HJ. The aged cardiovascular risk patient. Br J Anaesth, 2000; 85: 763-778.

12. Fleg JL, Lakatta EG. Role of muscle loss in the age-associated reduction in $\mathrm{VO}_{2}$ max. J Appl Physiol, 1988; 65: 1147-1151.

13. Hawkins AS, Wiswell RA. Rate and mechanism of maximal oxygen consuption decline with aging. Implication for exercise training. Sports Med, 2003; 33: 877-888.

14. Fletcher GF, Balady GJ, Amsterdam EA et al. Exercise standards for testing and training: A statement for healthcare professionals from the American Heart Association. Circulation, 2001; 104: 1694-740.
15. Forman DE, Clare R, Kitzman DW et al. Relationship of age and exercise performance in patients with heart failure: The HF-ACTION study. Am Heart J, 2009; 158: S6-S15.

16. Arena R, Myers J, Abella J et al. Cardiopulmonary exercise testing is equally prognostic in young, middle-aged and older individuals diagnosed with heart failure. Int J Cardiol, 2010; 151: 278-283.

17. Ciolac EG, Bocchi EA, Bortolotto LA, Carvalho VO, Greve JM, Guimaraes GV. Hemodynamic, metabolic, and neuro-humoralabormalities in young normotensive women at high familial risk for hypertension. J Hum Hypertens, 2010; 24: 814-822.

18. Wasserman K, Hansen JE, Sue DY, Stringer W, Whipp BJ. Principles of exercise testing and interpretation. $4^{\text {th }}$ Ed. Lippincott Williams and Wilkins, Philadelphia 2004: 160-182.

19. Brawner CA, Ehrman JK, Schairer JR, Cao JJ, Keteyian SJ. Predicting maximum heart rate among patients with coronary heart disease receiving beta-adrenergic blockade therapy. Am Heart J, 2004; 148: 910-914.

20. Tanaka H. Habitual exercise for the elderly. Fam Community Health, 2009; 32 (1 Suppl.): S57-S65.

21. Fleg JL, Morrell CH, Bos AG et al. Accelerated longitudinal decline of aerobic capacity in healthy older adults. Circulation, 2005; 112: 674-682.

22. Guimarães GV, Silva MSV, d'Avila VM, Ferreira SMA, Silva CP, Bocchi EA. Peak VO2 and VE/VCO2 slope in beta-blockers era in patients with heart failure: a Brazilian experience. Arq Bras Cardiol, 2008; 91: 39-45.

23. Hawkins SA, Wiswell RA. Rate and mechanism of maximal oxygen consumption decline with aging. Sports Med, 2003; 33: 877-888.

24. Lainscak M, Moullet C, Schon N, Tendera M. Treatment of chronic heart failure with carvedilol in daily practice: The SATELLITE survey experience. Int J Cardiol, 2007; 122: 149-155.

25. Carvalho VO, Rodrigues Alves RX, Bocchi EA, Guimarães GV. Heart rate dynamic during an exercise test in heart failure patients with different sensibilities of the carvedilol therapy: heart rate dynamic during exercise test. Int J Cardiol, 2010; 142: 101-104.

26. Fernandes Silva MM, Bacal F, Roque JM et al. Age-related maximum heart rate among ischemic and nonischemic heart failure patients receiving $\beta$-blockade therapy. J Card Fail, 2012; 18: 831-836.

27. Richards DR, Mehra MR, Ventura HO et al. Usefulness of peak oxygen consumption in predicting outcome of heart failure in women versus men. Am J Cardiol, 1997; 80: 1236-1238. 